\title{
Tumor immune microenvironment in epidermal growth factor receptor-mutated non-small cell lung cancer before and after epidermal growth factor receptor tyrosine kinase inhibitor treatment: a narrative review
}

\author{
Lihui Liu $^{1 \#}$, Chao Wang ${ }^{1 \#}$, Sini $\mathrm{Li}^{1}$, Hua Bai ${ }^{1,2}$, Jie Wang ${ }^{1,2}$ \\ ${ }^{1}$ National Cancer Center/National Clinical Research Center for Cancer/Cancer Hospital, Chinese Academy of Medical Sciences and Peking Union \\ Medical College, Beijing, China; ${ }^{2}$ State Key Laboratory of Molecular Oncology, Department of Medical Oncology, National Cancer Center/ \\ National Clinical Research Center for Cancer/Cancer Hospital, Chinese Academy of Medical Sciences and Peking Union Medical College, Beijing, \\ China \\ Contributions: (I) Conception and design: All authors; (II) Administrative support: J Wang, H Bai; (III) Provision of study materials or patients: \\ None; (IV) Collection and assembly of data: L Liu, C Wang; (V) Data analysis and interpretation: L Liu, C Wang, S Li; (VI) Manuscript writing: All \\ authors; (VII) Final approval of manuscript: All authors. \\ \#These authors contributed equally to this work. \\ Correspondence to: Jie Wang, MD, PhD; Hua Bai, MD, PhD. State Key Laboratory of Molecular Oncology, Department of Medical Oncology, \\ National Cancer Center/National Clinical Research Center for Cancer/Cancer Hospital, Chinese Academy of Medical Sciences \& Peking Union \\ Medical College, Beijing 100021, China. Email: zlhuxi@163.com; huabaihb@sina.com.
}

Objective: To review and summarize the characteristics of the tumor immune microenvironment (TIME) in EGFR-mutated non-small cell lung cancer (NSCLC) after EGFR-TKI treatment and its role in TKI resistance.

Background: Lung cancer is one of the most commonly diagnosed cancer and the leading cause of death from cancer in both men and women around the world. Epidermal growth factor receptor tyrosine kinase inhibitors (EGFR-TKIs) are considered a first-line treatment for EGFR-mutated NSCLC. However, almost all patients eventually develop acquired resistance to EGFR-TKIs, with a median progression-free survival (PFS) of 9-14 months. As immunotherapy has developed, it has become apparent that interactions between the TIME and tumor cells also affect EGFR-TKI treatment. The TIME comprises a variety of components but previous studies of the TIME following EGFR-TKI therapy of NSCLC are inconsistent. Here, we reviewed the characteristics of the TIME in NSCLC after EGFR-TKI treatment and its role in TKI resistance.

Methods: PubMed, Embase, and Web of Science were searched to July 1, 2021 with the following key words: "NSCLC", "EGFR", and "immunotherapy".

Conclusions: The TIME of EGFR-mutated NSCLC is different from that of non-mutated NSCLC, an explanation for EGFR-mutated NSCLC displaying a poor response to ICIs. The TIME of EGFR-mutated NSCLC also changes during treatment with EGFR-TKIs. The TIME in EGFR-TKI-resistant lung cancer can be summarized as follows: (I) compared with EGFR-TKI-sensitive tumors, EGFR-TKI-resistant tumors have a greater number of immunosuppressive cells and fewer immune-activated cells, while the tumor microenvironment is in an immunosuppressive state; (II) tumor cells and immunosuppressive cells secrete multiple negative immune regulatory factors, inhibit the recognition and presentation of tumor antigens and the antitumor effect of immune cells, resulting in immune escape; 3.EGFR-TKI-resistant tumors promote EMT. These three characteristics interact, resulting in a regulatory signaling network, which together leads to EGFR-TKI resistance. 


\begin{abstract}
Keywords: Non-small cell lung cancer (NSCLC); epidermal growth factor receptor mutation (EGFR mutation); epidermal growth factor receptor tyrosine kinase inhibitors (EGFR-TKIs); tumor immune microenvironment (TIME)
\end{abstract}

Submitted Jul 16, 2021. Accepted for publication Sep 03, 2021.

doi: $10.21037 /$ tlcr-21-572

View this article at: https://dx.doi.org/10.21037/tlcr-21-572

\section{Introduction}

Lung cancer is one of the most commonly diagnosed cancer and the leading cause of death from cancer in both men and women around the world, with a 5 -year survival rate of approximately $21 \%$ (1). According to global cancer statistics, the incidence of lung cancer and mortality in the male population ranks first globally for malignant tumors, while its incidence in the female population ranks third, and mortality ranks second (2). In China, the incidence of lung cancer and the mortality rate are highest in the male population, while the incidence in females is second, with the highest mortality rate (3).

Epidermal growth factor receptor (EGFR), also known as ERBB1 and HER1, is a transmembrane tyrosine kinase receptor (RTK) and a member of the human epidermal receptor (HER) family, representing a crucial component of cell signal pathways (4). Overexpression and mutation of EGFR can lead to activation of important signaling pathways, such as Ras-MAPK, PI3K-Akt, and STAT, resulting in increased cell proliferation, angiogenesis, and metastasis (5). Approximately $40-80 \%$ of patients with nonsmall cell lung cancer (NSCLC) have an EGFR mutation or it is overexpressed (6). EGFR mutations have been found in $15 \%$ of Caucasian and $30-50 \%$ of Asian NSCLC patients (7-9). Epidermal growth factor receptor tyrosine kinase inhibitors (EGFR-TKIs), classic small molecule inhibitors, inhibit the EGFR tyrosine kinase domain reversibly through competitive binding with ATP (10). At present, EGFR-TKIs commonly used in the clinic include the first generation treatments gefitinib and erlotinib, second generation afatinib and dacomitinib, and osimertinib, a third-generation treatment. Several clinical trials have demonstrated that EGFR-TKIs can prolong the survival of patients with tumors harboring EGFR-activating mutations (11-33). The principal clinical trials are displayed in Table 1.

However, patients initially responding to EGFR-TKIs invariably develop resistance, resulting in median progressionfree survival (PFS) of approximately 10 months $(11,16,23,30)$.
Resistance to EGFR-TKIs is inevitable due to a number of mechanisms, including the secondary mutation known as T790M (50\%) (34), MET amplification (5\%), HER2 amplification (8\%), PI3K mutation (5\%), histologic transformation $(14 \%)(35,36)$, and new mutations such as EFGR-C797S, EGFR-L792H, and EGFR-G796R (37-39). There has been too great a focus in previous studies on drug resistance caused by tumor cells, and too little on the tumor immune microenvironment (TIME). It is therefore imperative that the mechanisms of the TIME are studied regarding tumor drug resistance. The TIME comprises numerous cell types in addition to cancer cells, including bone marrowderived inflammatory cells, lymphocytes, fibroblastic cells, in addition to extracellular matrix (ECM) composed of collagen and proteoglycans $(40,41)$. The review will describe in detail the TIME of EGFR-mutated NSCLC from five perspectives: tumor-infiltrating immune cells; cytokines secreted by tumor and immune cells; tumor ECM; cancer-associated fibroblasts $(\mathrm{CAFs})$; and the tumor vasculature.

We present the following article in accordance with the Narrative Review checklist (available at https://dx.doi. org/10.21037/tlcr-21-572).

\section{Tumor-infiltrating immune cells}

The majority of research on the TIME at present has focused on tumor-infiltrating immune cells. Almost all immune cell types can be found in the tumor microenvironment, including tumor-associated macrophages (TAMs), dendritic cells (DCs), natural killer cells (NKs), B lymphocytes (B cells), T lymphocytes ( $\mathrm{T}$ cells), marrow-derived suppressor cells (MDSCs), neutrophils, etc. (42). Immune cells play an important role in shaping the TIME in EGFR-mutant lung cancer by secreting cytokines and activating signal pathways (Figure 1).

\section{TAMs}

Macrophages originate from progenitors in the bone 
Table 1 Clinical trials of EGFR-TKI in EGFR mutated NSCLC

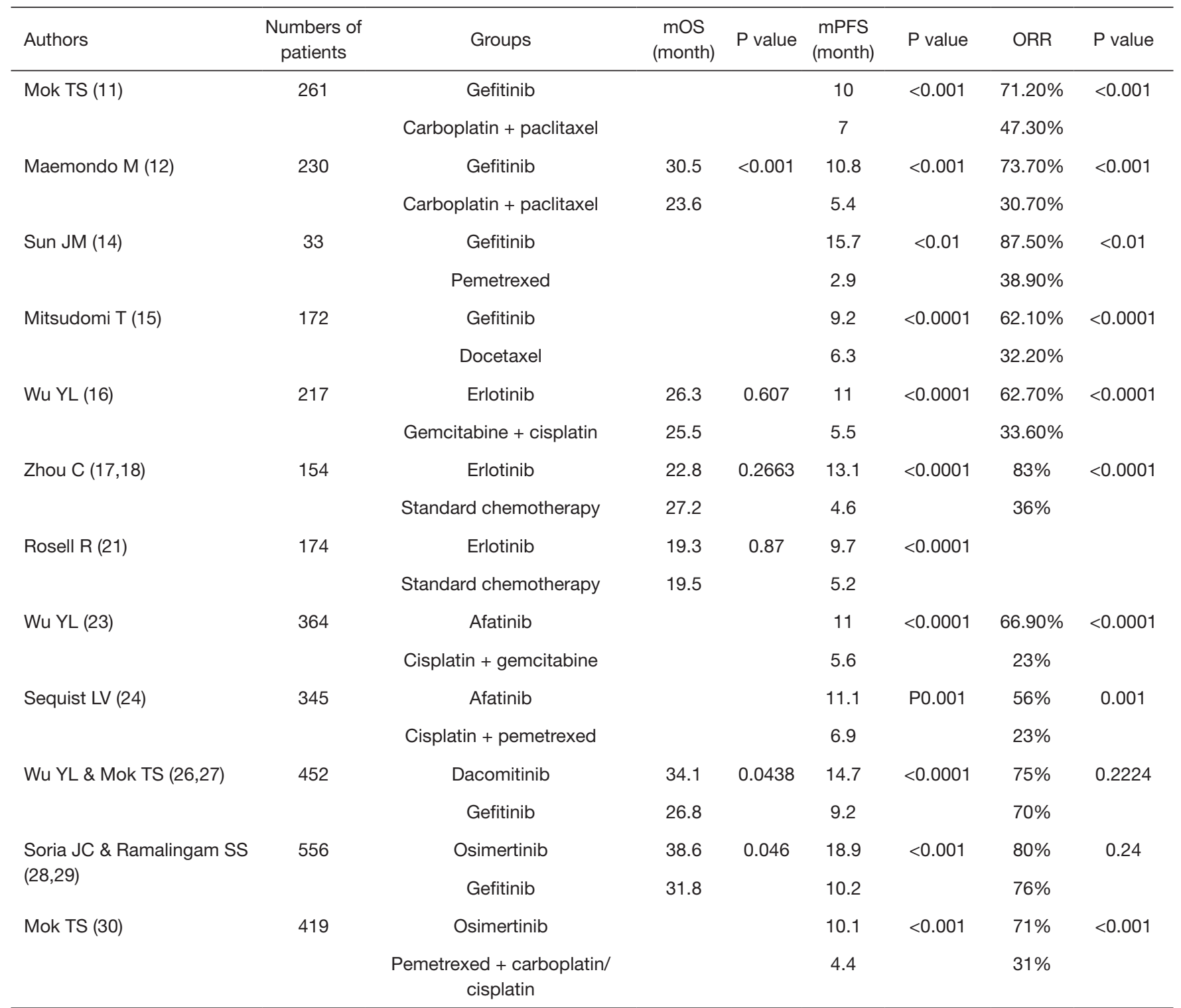

EGFR, epidermal growth factor receptor; TKI, tyrosine kinase inhibitor; NSCLC, non-small cell lung cancer; mOS, median overall survival; $\mathrm{mPFs}$, median progression free survival; ORR, objective response rate.

marrow and enter the peripheral blood. During homeostasis and inflammation, they migrate into tissues and differentiate into macrophages following exposure to local growth factors, proinflammatory cytokines, and microbial products. Macrophages have multiple functions in tumors (43). Studies have found that the number of CD68+ and CD204+ TAMs in EGFR-mutant NSCLC tumor tissues is less than that observed in tumors with wild-type EGFR, with a superior prognosis (44). Furthermore, EGFR-mutated lung cancer with high levels of infiltrating CD204+ TAMs was found to be highly aggressive with poor prognosis (45). In an additional study, it was observed that the resistance of lung cancer to EGFR-TKIs was correlated with the tumor infiltration of CD68+ TAMs and S100A9+ MDSCs, causing resistance through the NF- $\mathrm{NB}$ pathway (46). Two major macrophage subpopulations with different functions include the classically activated or inflammatory (M1) phenotype and the alternatively activated or anti-inflammatory (M2) type. M1 macrophages exhibit robust anti-tumoral activity whereas M2 macrophages promote tumor formation and 
EGFR-TKls sensitive

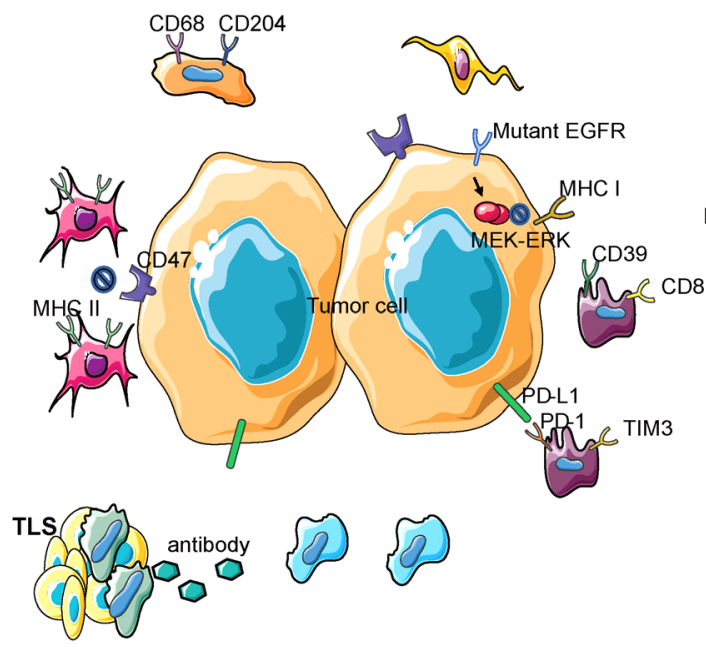

EGFR-TKIs resistance

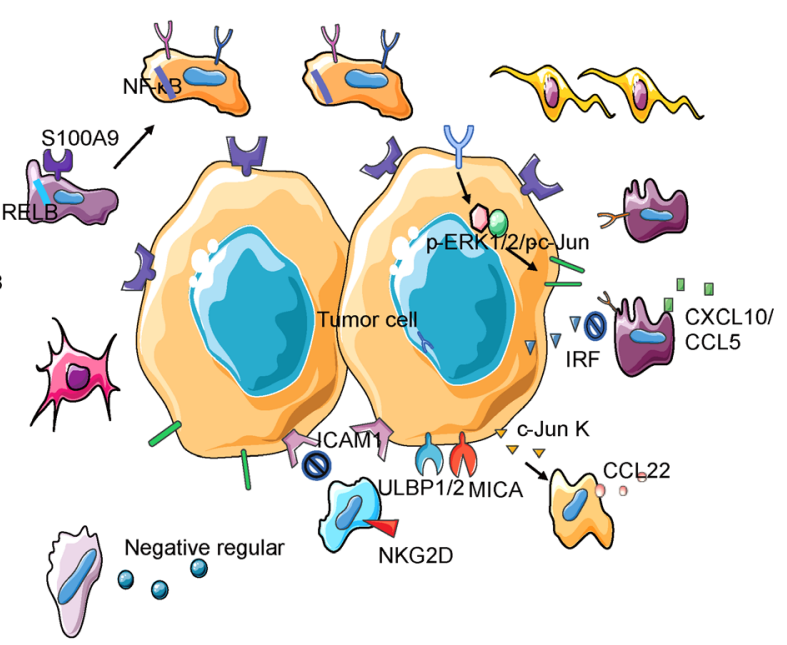

Q

Figure 1 Immune cells in the TIME of EGFR mutant lung cancer. The number of neutrophils, MDSCs, and CD68+ and CD204+ TAMs (M2) in EGFR-TKI-sensitive lung cancer is less than that in EGFR-TKI-resistant lung cancer. However, the number of MHC II+ DC and NK cells in EGFR-TKI-sensitive lung cancer is more than in EGFR-TKI-resistant lung cancer. S100A9+ MDSCs transform into M2 type TAMs by activation of the RELB gene, while TAMs (M2) induce EGFR-TKI resistance via the NF- $\kappa B$ pathway. EGFR-TKI-resistant lung cancer cells express CD47 which blocks the phagocytosis and antigen presentation by DCs. Up-regulation of ULBP1, 2, and MICA expression on tumor cells and NKG2D on NK cells can promote NK cytotoxicity toward tumor cells. B cells are present within a TLS associated with good prognosis. B cells also differentiate into plasma cells, producing specific antibodies and recognizing tumor-associated antigens. Breg weakens the response of T cells and NK cells, facilitating the immune-suppressive activity of regulatory T cells (Tregs) by secreting immunosuppressive factors. The number of T cell-like CD39+ and CD8+ or PD-1+ and TIM3+ T cells in EGFR-mutant lung cancer are fewer than in wild-type EGFR lung cancer. T cell apoptosis is caused by an EGFR mutation that increases the expression of PDL1 via the p-ERK1/2/p-c-jun pathway. The number of Tregs in EGFR-mutant NSCLC was fewer than in non-EGFR mutant NSCLC. EGFR signaling activates cJun/cJun N-terminal kinase and reduces interferon regulatory factor-1. The former increases CCL22 expression, which recruits CD4+ regulatory T cells, and the latter decreases CXCL10 and CCL5 expression, which induces CD8+ T cell infiltration. EGFR mutations also decrease the expression of MHC-I via the MEK-ERK pathway. TIME, tumor immune microenvironment; EGFR, epidermal growth factor receptor; MDSC, marrow-derived suppressor cell; TKI, tyrosine kinase inhibitor; MHC, major histocompatibility complex; NK, natural killer; TAM, tumor-associated macrophage; DC, dendritic cell; NSCLC, non-small cell lung cancer.

progression (47). CD68+ and CD204+ TAMs are M2 macrophages. It has been found that the proportion of $\mathrm{M} 2$ macrophages in EGFR-TKI resistant lung cancer is higher than in EGFR-TKI sensitive lung cancer (48). Therefore, it can be inferred that EGFR-TKI resistance is related to M2type TAMs, and that reducing the number of M2 TAMs may reverse EGFR-TKI resistance.

\section{$D C s$}

DCs are unique immune cells that link the innate and adaptive immune response. They are considered the most effective type of antigen-presenting cell, playing an important role in the process of tumor antigen recognition and presentation (49). It has been found that the proportion of major histocompatibility complex class II (MHC-II)positive DCs in EGFR-TKI sensitive tumors is higher than in EGFR-TKI resistant tumors (50). Another study found that lung cancer with the EGFR mutation inhibits the maturation of DCs and induces the production of anergic DCs that represses antitumor immunity through exosomes (51). Analysis of NSCLC transcriptomic datasets reveal selective overexpression of CD47 in patients with the EGFR mutation. EGFR-TKIs significantly reduce 
CD47 expression on the surface of pre-apoptotic cells, favoring more efficient engulfment of cancer cells by DCs. CD47 expression becomes up-regulated following the development of EGFR-TKI resistance, and blockade of this protein using a specific monoclonal antibody increases the clearance of EGFR-TKIs resistant cells by phagocytes (52). Therefore, EGFR-TKI resistance is associated with decreased numbers of DCs and their dysfunction.

\section{NK cells}

NK cells are lymphocytes of the innate immune system that monitor the cell surface of autologous cells for aberrant expression of MHC-I molecules and cell stress markers, which play an important role in the antitumor immune response (53). The study found that patients with a high number of NK cells had greater overall survival (OS) and PFS. The number of NK cells was found to increase after EGFR-TKI treatment (54). For EGFR-TKI resistant lung cancer, up-regulation of ICAM1 was found to induce drug resistance, while NK92-CD16 cells combined with the EGFR antibody were found to reverse drug resistance (55). Another study found that gefitinib greatly enhanced NK cell cytotoxicity toward lung cancer cells with the EGFR L858R+T790M resistance mutation. Gefitinib has been shown to block immune escape by up-regulation of the expression of the NKG2D ligands ULBP1, ULBP2, or MICA on tumor cells and NKG2D on NK cells in a coculture system (56). A combination of EGFR-TKIs and NK cell adoptive immunotherapy possibly represents an effective strategy for EGFR-TKI resistant lung cancer.

\section{Myeloid-derived suppressor cells (MDSCs)}

MDSC arise from the bone marrow and support tumor progression by the promotion of tumor cell survival, angiogenesis, invasion of healthy tissue by tumor cells, and metastases (57). There are two large groups of MDSCs, termed granulocytic or polymorphonuclear MDSCs (PMN-MDSCs), phenotypically and morphologically similar to neutrophils, and monocytic MDSCs (M-MDSC), phenotypically and morphologically similar to monocytes (58). It has been found that the presence of a high number of MDSCs in EGFR-mutant lung cancer was correlated with poor prognosis, and a reduction in MDSC numbers able to improve prognosis (59). In addition, the numbers of S100A9-positive MDSCs in EGFR-TKI- resistant lung cancer were found to be higher than in healthy donors. Further study has found that this type of MDSC can be transformed into an M2 TAM by activation of the RELB gene, thus promoting the proliferation and metastasis of tumors and resulting in EGFR-TKI resistance (46). Few studies have so far been published on the mechanism by which MDSCs participate in EGFRTKI resistance. Whether inhibition of MDSCs can reverse EGFR-TKI resistance requires additional study.

\section{Neutrophils}

Neutrophils represent the largest cohort of immune cells and in humans are generally considered a non-complex front-line defender of the innate immune system. Recent studies have demonstrated that neutrophils are also associated with the anti-tumor immune response (60). Several studies have shown that a low neutrophil-tolymphocyte ratio was a good prognostic factor in EGFRmutant NSCLC patients receiving EGFR-TKI treatment (61-63). Another study demonstrated that intratumoral neutrophil density was lower in EGFR-mutant NSCLC in comparison with non-EGFR mutant NSCLC (64). Few studies have reported on the mechanism and relationship between neutrophils and EGFR-TKI resistance. Whether neutrophils are related to EGFR-TKI resistance requires additional study.

\section{B cells}

B cells are an important element of the human adaptive and humoral immune response. Studies have demonstrated that B cells play an important role in the anti-tumor immune response (65). According to analysis using data from the TCGA database, the abundance of tumor-infiltrating B cells (TIBs) is significantly higher in NSCLC with the EGFR mutation (66). Studies have found that B cells are usually found within an ectopic tissue called the tertiary lymphoid structure (TLS), the existence of which is associated with good prognosis (67). The principal function of B cells is participation in the humoral immune response. In lung tissue, B cells differentiate into plasma cells, which produce specific antibodies and recognize tumor-associated antigens $(67,68)$. In addition, activated TIBs can activate tumorinfiltrating $\mathrm{T}$ cells (TITs) by being presenting them with tumor antigens and activation of the TIT anti-tumor effect (69). However, regulatory B cells (Bregs), a subtype of $\mathrm{B}$ cells, can inhibit immunity and promote tumor 
proliferation and metastasis (70). It has been found that Bregs can weaken the response of T cells and NK cells and facilitate the immune-suppressive activity of regulatory $\mathrm{T}$ cells (Tregs) by up-regulation of immunoregulatory ligands through secretion of immunosuppressive factors such as IL10 and TGF- $\beta$ (71). The relationship between B cells and EGFR-TKIs is complex and requires additional study.

\section{T cells}

$\mathrm{T}$ cells are an important component of the human adaptive and cellular immune response. They play an important role in the anti-tumor immune response and are the most studied immune cell in the TIME (72). T cells consist of different subpopulations, including naïve $\mathrm{T}$ cells that can respond to new antigens, memory $T$ cells that are activated from previous antigens and maintain long-term immunity, and regulatory $\mathrm{T}$ cells that regulate the immune response (72). With the breakthrough of immunotherapy in the cancer treatment, oncologists began to explore whether immunotherapy could be applied to EGFR mutant NSCLC. Unfortunately, clinical evidence showed that most of the patients with EGFR-mutated NSCLC would not benefit from the immunotherapy (73-75). It has been found that the percentage of TITs in EGFR-mutant NSCLC was lower than in non-EGFR mutated-NSCLC, while a low percentage of TITs is predictive of poor prognosis (76). Another study found that the number of CD8+ CD39+ T cells in EGFR mutant-NSCLC patients was less than that in wild-type EGFR NSCLC patients. The study suggested that CD39+ T cells were associated with a positive effect of immune checkpoint inhibitors (ICIs) (77). Furthermore, it was found that the number of CD8+ TIT cells in EGFRmutant NSCLC was less than that in wild-type EGFR NSCLC (78), and the proportion of PD-L1+ or PD-1+ in the CD8+ $\mathrm{T}$ cell population was also less than nonEGFR mutant NSCLC $(79,80)$. This was also confirmed by animal experiments of genetically engineered mice with the EGFR mutation. The study found that the number of CD8+ TITs in mice with the EGFR mutation was less than in mice with wild-type EGFR or other gene mutations (81). These studies partially explained the poor efficacy of EGFR mutant NSCLC when using ICIs. T cell immunoglobulin and mucin domain containing protein 3 (TIM3) is a member of the TIM family. Studies have found that the number of TIM3 + T cells in EGFR-mutant NSCLC tumors is fewer than in wild-type EGFR tumors, while $\mathrm{T}$ cells that are TIM3 positive can be CD8+ T cells, CD4+ T cells, or NKT cells (82).

When comparing patients before and after EGFRTKI treatment, studies have found that the total number of $\mathrm{T}$ cells, and the number of CD4+ and CD8+T cells in patients with the EGFR mutation were not significantly different, but the ratio of CD4+/CD8+ T cells increased, a high ratio being associated with poor prognosis (54). Studies have found that $\mathrm{T}$ cell apoptosis was caused by the EGFR mutation which increased the expression of PDL1 through the p-ERK1/2/p-c-jun pathway. EGFR-TKIs prevent $\mathrm{T}$ cell apoptosis and inhibit tumor proliferation by decreasing the expression of PD-L1 through inhibition of the EGFR pathway (83). Another study found that the number of Tregs in EGFR-mutant NSCLC was less than in non-EGFR mutant NSCLC, due to EGFR signaling causing activation of cJun/cJun N-terminal kinase and reducing the quantity of interferon regulatory factor- 1 . The former increased CCL22 expression, which recruits CD4+ regulatory $\mathrm{T}$ cells, and the latter decreased CXCL10 and CCL5 expression, which induce CD8+ T cell infiltration. EGFR-TKIs can reverse this phenomenon by inhibiting the EGFR signaling pathway (84). The anti-tumor response of $\mathrm{T}$ cells occurs as a result of the recognition of the tumor antigen presented by MHC-I. Studies have found that the EGFR mutation decreases the expression of MHC-I via the MEK-ERK pathway. EGFR-TKIs increase the expression of MHC-I by inhibiting the EGFR pathway, and recruit T cells to the tumor. Therefore, the number of $\mathrm{CD} 8+\mathrm{T}$ cells in the tumor following EGFR-TKI treatment is greater than prior to treatment (85).

A classification based on PD-L1 and CD8-positive tumor-infiltrating lymphocyte (TIL) status has been proposed. The outcomes of patients with negative PD-L1 expression and a high CD8+ TIL count were found to be significantly superior to patients that did not. In patients with positive PD-L1 and high numbers of CD8+ TIL, the rate of EGFR mutation was significantly lower than in the non-EGFR mutation (86). Moreover, for positive PD-L1 and high CD8+TIL NSCLC with the EGFR mutation, the prognosis after EGFR-TKI therapy is poor, but this type of NSCLC is likely to respond to ICI $(87,88)$. A different study found that the proportion of $\mathrm{PD}-\mathrm{L} 1$ positive $\mathrm{T}$ cells in the peripheral blood of patients with the EGFR mutation was less than in patients without the EGFR mutation. However, the proportion of PD-L1+ T cells in the peripheral blood of patients with the EGFR mutation was significantly higher after EGFR-TKIs treatment. Moreover, PD-L1+ T cells are positively correlated with the poor 
response of EGFR-TKIs (89). For uncommon EGFRmutant tumors, including G719X, L861Q, S768I, and Ex20 ins, PD-L1 expression in tumor cells was higher than in common EGFR mutant tumors. Moreover, the proportion of CD8+ TIL in uncommon EGFR-mutant tumors was greater than in common EGFR mutant tumors. Patients with high PD-L1 expression and abundant CD8+TIL exhibit a poor response to EGFR-TKIs, but respond better to ICIs (90). Many studies have been published in which the mechanisms of EGFR-TKI resistance are diverse in patients with the EGFR mutation. Therefore, therapeutic strategies involving $\mathrm{T}$ cells represent a promising field of research for reversal of EGFR-TKI resistance.

\section{Cytokines secreted by tumor and immune cells}

Cytokines are small molecular proteins with diverse biological properties, and are synthesized and secreted by both immune and non-immune cells following stimulation, including interleukins, interferon, members of the tumor necrosis factor superfamily, colony-stimulating factors, chemokines, growth factors, etc. (91). They play an important role in tumor inhibition, proliferation, and metastasis (Figure 2). Studies have found that in EGFRmutant lung cancer, alveolar macrophages downregulate surface expression of MHC-II and costimulatory molecules, they exhibit increased production of CXCL1, CXCL2, and IL1 receptor antagonist, and display increased levels of phagocytosis. EGFR-TKIs decrease the number of alveolar macrophages in EGFR-mutant lung cancer (92). It has been found that EGFR-TKIs induce PD-L1 protein degradation in EGFR-mutated NSCLC cells via the GSK3 $\beta$ and ubiquitin protease pathways, contributing to $\mathrm{T}$ cell activation (93). In addition, EGFR mutations can upregulate amphiregulin (AREG) which maintains Treg suppression via the EGFR/GSK-3 $3 /$ Foxp 3 axis. Furthermore, inhibition of EGFR by EGFR-TKIs restores GSK-3 $\beta$ activity and attenuates Treg cellular function (94).

It has been found that Axl kinase is overexpressed in EGFR-TKI resistant NSCLC, and is positively correlated with the expression of genes encoding immune checkpoint molecules (CD274, CTLA4), chemokine receptors (CXCR4, CXCR6), and chemokines (CXCL16). Chemokines can induce tumor invasion and metastasis. Inhibition of Axl kinase activity can reduce the expression of these chemokines (95). In addition, studies have found that overexpression of hepatocyte growth factor (HGF) induces EMT through the HGF-MET pathway, resulting in EGFR-TKI resistance (96-104). MiR-1-3p and miR206 can reverse HGF-induced EGFR-TKI-resistant lung cancer through inhibition of c-Met signaling and EMT (105). Overexpression of PD-L1 is a mechanism of primary EGFR-TKI resistance. Studies have found that this resistance occurs by induction of EMT via the TGF- $\beta$ / Smad3 pathway. Inhibition of the TGF- $\beta /$ Smad 3 pathway reverses EGFR-TKI resistance (106-108). Moreover, activation of the TGF- $\beta / \mathrm{Smad} 2$ pathway induces EMT and EGFR-TKI resistance by increasing the expression of CXCR4 $(108,109)$. An additional study found that TGF- $\beta$ can also induce EMT and EGFR-TKI resistance by increasing the expression of PKC $\alpha$ (110). In addition, TGF- $\beta 1$ can induce EGFR-TKI resistance by activating the Akt-ERK pathway, increasing the expression of MIG6, and decreasing the expression of PTEN $(111,112)$.

It has been found that overexpression of IL-6 in EGFR-mutant NSCLC was correlated with EGFR-TKI resistance (113). In addition, activation of the adrenergic $\beta 2$ receptor can induce EGFR-TKI resistance by increasing the expression of IL-6 (114). In NSCLC patients with the EGFR mutation, the study found that high levels of IL6, VEGF, and HGF in serum were associated with a poor response to EGFR-TKI treatment. Dynamic changes in these cytokines in blood during TKI treatment predicted the efficacy of EGFR-TKIs $(115,116)$. Studies have found that RNF25 promotes EGFR-TKI resistance in EGFRmutant NSCLC cells by inducing ERK reactivation through the expression of IL6 via the NK- $\mathrm{\kappa B}$ signaling pathway, while inhibition of RNF25 or the NF- $\kappa \mathrm{B}$ and ERK pathways can reverse EGFR-TKI resistance (117). In addition, studies have found that overexpression of miR-762 induced by IL6 promotes EGFR-TKI resistance in NSCLC by post-transcriptional repression of active BCR-related protein (ABR) (118). Not only is it IL-6 that can induce EGFR-TKI resistance, but IL-8 can also induce EGFRTKI resistance by EMT through activation of the MAPK signaling pathway (119).

Integrin-linked kinase (ILK) regulates interactions between tumor cells and the extracellular environment, activating signaling pathways, and promoting cell proliferation, migration, and EMT. SHP2 is critical for the activation of the RTK signaling pathway. Studies have found that ILK and SHP are highly expressed in EGFRTKI resistant NSCLC (120). Other studies have found that secreted phosphoprotein 1 (SPP1) is significantly increased in EGFR-TKI resistant lung cancer cells, and inhibition of SPP1 increases sensitivity of lung cancer cells 


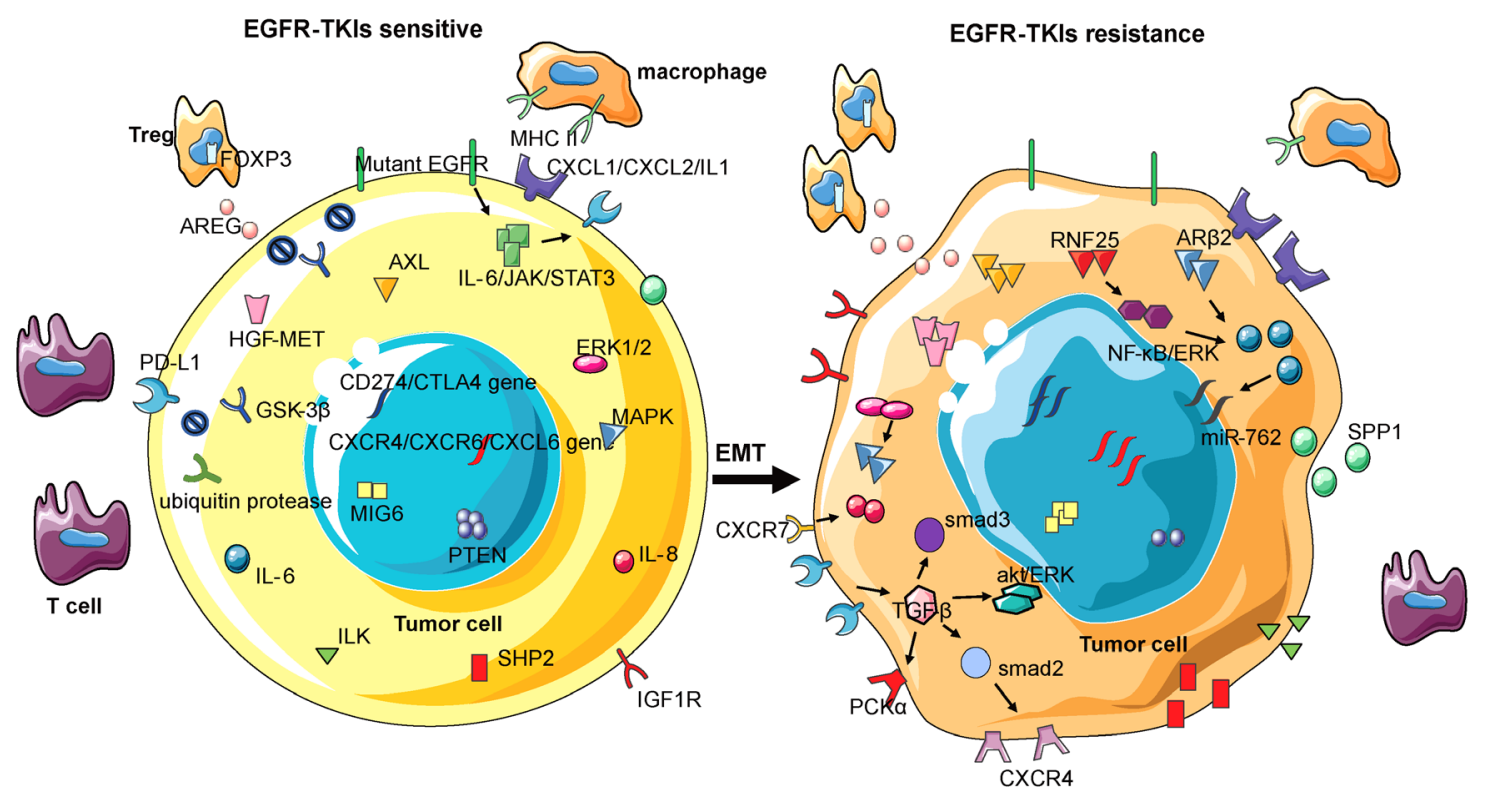

Figure 2 Cytokines in the TIME of EGFR-mutant lung cancer. EGFR-TKIs can induce PD-L1 protein degradation via the GSK3 $\beta$ and ubiquitin protease pathways, contributing to $\mathrm{T}$ cell activation. EGFR mutation can up-regulate amphiregulin (AREG), which maintains Treg suppressive function via the EGFR/GSK-3ß/Foxp3 axis. Axl kinase, genes encoding immune checkpoint molecules (CD274, CTLA4), chemokine receptors (CXCR4, CXCR6), or chemokines (CXCL16) are overexpressed in EGFR-TKI resistant NSCLC. Overexpression of hepatocyte growth factor (HGF) induces EMT via the HGF-MET pathway, resulting in EGFR-TKI resistance. PD-L1 induces EMT via the TGF- $\beta / \mathrm{Smad} 3$ pathway. Activation of the TGF- $\beta / \mathrm{Smad} 2$ pathway can also induce EMT by increasing the expression of CXCR4. Furthermore, TGF- $\beta$ can induce EMT and EGFR-TKI resistance by increasing the expression of PCK $\alpha$, activation of the Akt-ERK pathway, increasing MIG6 expression, and decreasing PTEN expression. Adrenergic $\beta 2$ receptors can induce EGFR-TKI resistance by increasing the expression of IL-6. RNF25 promotes EGFR-TKI resistance by inducing ERK reactivation by the expression of IL6 via the NK-кB signaling pathway. ILK, SHP, SPP1, and IGF1R are highly expressed in EGFR-TKI-resistant NSCLC. CXCR7 can promote EGFR-TKI-resistance by the EMT of tumor cells through activation of the MAPK-ERK pathway via $\beta$-arrestin. TIME, tumor immune microenvironment; EGFR, epidermal growth factor receptor; TKI, tyrosine kinase inhibitor; NSCLC, non-small cell lung cancer; EMT, epithelial mesenchymal transition.

to EGFR-TKIs, decreasing the possibility of invasion (121). Overexpression of type 1 insulin-like growth factor receptor (IGF1R) is associated with EGFR-TKI resistance. Studies have found that overexpression of IGF1R can promote EGFR-TKI resistance by inducing EMT in tumor cells, and inhibition of IGF1R can reverse EMT in tumor cells and sensitivity to EGFR-TKIs (122). CXCR7, an atypical $\mathrm{G}$ protein-coupled receptor, can promote EGFR-TKI resistance by the EMT of tumor cells through activation of the MAPK-ERK pathway via $\beta$-arrestin (123). Multiple studies have been published in which the relationship between cytokines and EGFR mutation with EGFR-TKI resistance has been investigated, involving complex and diverse signaling pathways, classified generally as tumor EMT. Therefore, inhibitors targeting multiple pathways of
EMT may represent an appropriate research direction for investigating the reversal of EGFR-TKI resistance.

\section{ECM}

ECM is the non-cellular component present within all tissues and organs, and provides not only essential physical scaffolding for the cellular constituents but also initiates crucial biochemical and biomechanical cues required for tissue morphogenesis, cellular differentiation, and homeostasis (124). Interactions between EGFR-mutated NSCLC tumor cells and the ECM are important in tumor development (Figure 3A). EGFR mutations can increase the expression of twist, snail, and other genes during tumor development, resulting in the induction of epithelial- 
A

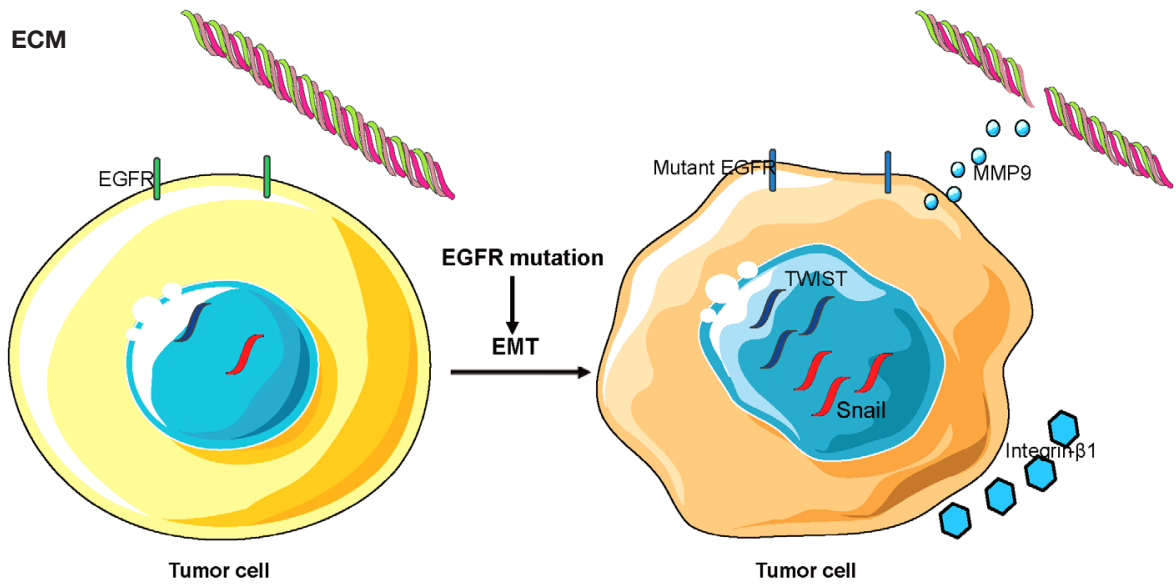

B

ECM

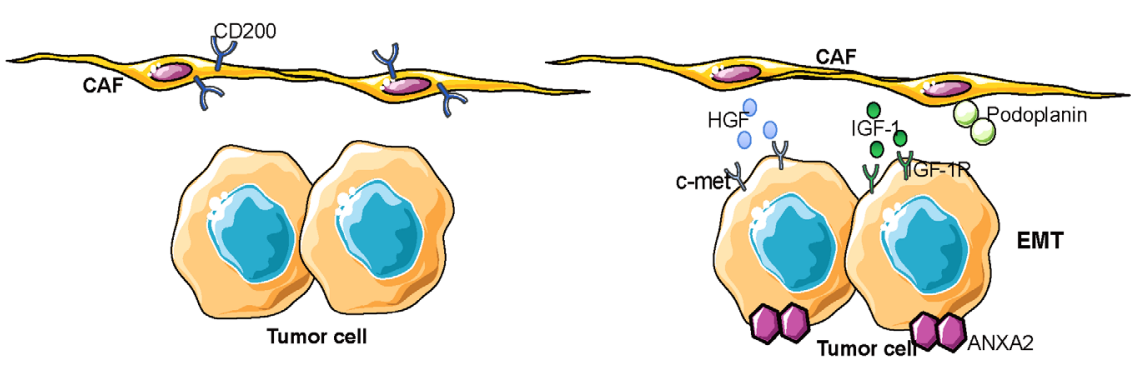

EGFR-TKI sensitive

EGFR-TKI resistance

C

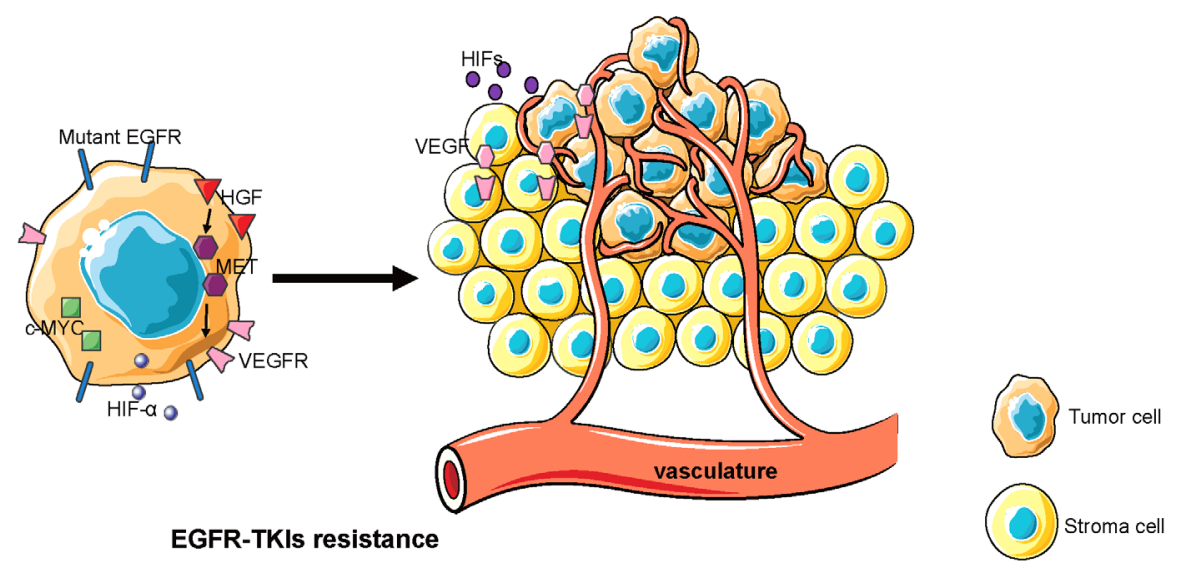

Figure 3 The ECM, CAFs, and vasculature in the TIME of EGFR-mutant lung cancer. (A) The ECM in the TIME of EGFR-mutant lung cancer. EGFR-mutant lung cancer cells overexpress twist and snail, which induces EMT. They also overexpress MMP9, which destroys the ECM barrier. EGFR-TKI-resistant lung cancer cells highly express integrin- $\beta 1$. (B) CAFs in the TIME of EGFR-mutant lung cancer. In EGFR-TKI-sensitive lung cancer, CAFs highly express CD200. In EGFR-TKI-resistant lung cancer, CAFs highly express HGF and IGF1, which induce tumor cell overexpression of ANX2 and EMT. They also express podoplanin. (C) The vasculature in the TIME of EGFRTKI-resistant lung cancer. HGF expression promotes the activation of MET, which stimulates the production of VEGFR. Activation of c-MYC and overexpression of HIF- $\alpha$ also induces EGFR-TKI resistance. ECM, extracellular matrix; CAF, cancer-associated fibroblast; TIME, tumor immune microenvironment; EGFR, epidermal growth factor receptor; EMT, epithelial mesenchymal transition; MMP-9, matrix metalloproteinase-9; HGF, hepatocyte growth factor; IGF-1, type 1 insulin-like growth factor. 
mesenchymal transition (EMT) that promotes tumor cell invasion and metastasis. EGFR-TKIs can inhibit EMT and prevent tumor cell invasion and metastasis $(125,126)$. The activation of EGFR in tumor cells also increases the activity of matrix metalloproteinase-9 (MMP-9), which promotes the destruction of the ECM barrier and the invasiveness of tumor cells $(127,128)$. Over recent years, studies have found that the composition of the ECM is associated with EGFR-TKI resistance. The ECM of EGFR-TKI resistant tumor cells have a high expression of integrin- $\beta 1$, a collagen receptor, resulting in a large quantity of collagen surrounding tumor cells. EGFR-TKI-sensitive cell lines display EGFR-TKI resistance following their co-culture with integrin $\beta-1$ extracted from drug-resistant cell lines, with inhibition of integrin $\beta-1$ expression reversing EGFRTKI resistance (129). The ECM is the location of tumor, stromal, and immune cell interactions. The ECM contains multiple cytokines, proteins, and other soluble substances and so plays an important role in drug resistance. This suggests that there are multiple research avenues regarding the ECM to be studied in the future.

\section{CAFs}

CAFs are an important component of the tumor microenvironment and are activated by growth factors, direct intercellular communication, adhesion molecules, and other factors. Dissimilar to normal fibroblasts, CAFs are perpetually activated, do not return to a normal phenotype or undergo apoptosis, and promote tumor progression (130). CAFs play an important role in the malignant progression of cancer by releasing growth factors and cytokines which stimulate angiogenesis, cell proliferation, invasion, and metastasis (130). The function of CAFs in EGFR-TKI sensitive lung cancer is different from that in EGFRTKI resistant lung cancer (Figure 3B). In vitro and in vivo experiments have demonstrated that the expression and phosphorylation of ANXA2 in CAFs in EGFR-TKI resistant lung cancer are greater due to the secretion of the growth factors HGF and IGF-1, and by activation of the corresponding receptors c-met and IGF-1R, resulting in the induction of EMT in tumor cells and promotion of EGFRTKI resistance (131). In addition, CD200-positive CAFs in tumor tissues can augment the sensitivity of EGFR-mutant tumor cells to EGFR-TKIs (132). An additional study found that podoplanin-positive CAFs promote EGFR-TKI resistance in tumor cells while inhibition of podoplanin expression in CAFs reversed drug resistance (133). A recent study found that mesenchymal cells isolated from EGFRmutant lung cancer can differentiate into CAFs, promoting tumor invasion and metastasis (134). CAFs are therefore associated with EGFR-TKI resistance. Whether inhibition of CAFs can reverse EGFR-TKI resistance requires additional study.

\section{Tumor vasculature}

The tumor vasculature is an additional important component of the tumor microenvironment. The vasculature of a tumor arises from two different biological processes: angiogenesis consisting of the formation of new blood vessels from pre-existing vessels and vasculogenesis resulting in the formation of new blood vessels by the recruitment of circulating endothelial progenitor cells (135). Hypoxia inducible factors (HIFs) represent the principal signal regulating the process of angiogenesis which induces the transcription of genes responsible for the activation of angiogenesis (136). Another important regulator is vascular endothelial growth factor (VEGF) and its receptor (VEGFR), which can stimulate angiogenesis (137). The tumor vasculature in EGFR mutant lung cancer is different from that in wild-type EGFR lung cancer (Figure 3C). It was found that regions in lung adenocarcinoma with an EGFR mutation that had poor vasculature were smaller than in tumors without the EGFR mutation (138). Another study found that tumors with mutations in exon 20 and 21 of EGFR exhibited high expression levels of VEGFR, while those with mutations in exon 19 of EGFR exhibited low expression levels of VEGFR (139). For EGFR-TKI resistant NSCLC, heat shock protein 90 (Hsp90) inhibitors have been found to overcome HGF-triggered resistance to EGFR-TKIs by reducing EGFR protein expression and tumor angiogenesis (140). Another study found that Met activation by HGF stimulated the production of vascular endothelial growth factor (VEGF) and facilitated angiogenesis, indicating that HGF induces EGFR-TKI resistance and angiogenesis. Triple inhibition of EGFR, Met, and angiogenesis can usefully control the progression of EGFR-mutant lung cancer with HGF-triggered EGFRTKI resistance (141). In vivo and in vitro experiments with EGFR-TKIs combined with chemotherapy to treat EGFR-mutant lung cancer found that it inhibited tumor progression and angiogenesis by down-regulation of the c-MYC and HIF- $\alpha$ pathways (142). In addition, a clinical study of VEGFR2 inhibitor combined with EGFR-TKI in the treatment of EGFR mutant NSCLC found that 
VEGFR2 inhibitor combined with EGFR-TKI was better than EGFR-TKI monotherapy (143). The formation of a tumor vascular system is associated with EGFR-TKI resistance. Whether antiangiogenic therapy can reverse EGFR-TKI resistance and the associated mechanisms require further investigation.

\section{Conclusions and perspective}

In conclusion, the TIME of EGFR-mutated NSCLC is different from that of non-mutated NSCLC, an explanation for EGFR-mutated NSCLC displaying a poor response to ICIs. The TIME of EGFR-mutated NSCLC also changes during treatment with EGFRTKIs. The TIME in EGFR-TKI-resistant lung cancer can be summarized as follows: (I) compared with EGFRTKI-sensitive tumors, EGFR-TKI-resistant tumors have a greater number of immunosuppressive cells and fewer immune-activated cells, while the tumor microenvironment is in an immunosuppressive state; (II) tumor cells and immunosuppressive cells secrete multiple negative immune regulatory factors, inhibit the recognition and presentation of tumor antigens and the antitumor effect of immune cells, resulting in immune escape; (III) EGFR-TKI-resistant tumors promote EMT. These three characteristics interact, resulting in a regulatory signaling network, which together leads to EGFR-TKI resistance. Inhibition of one does not fundamentally reverse EGFR-TKI resistance. Therefore, future research on reversal of EGFR-TKI resistance requires the development of pan-targeting drugs that inhibit the key functions of the entire regulatory signaling network, influence immune cell infiltration and immune regulatory factors, reverse EMT, and finally reverse EGFRTKI resistance.

\section{Acknowledgments}

Funding: This study was supported by the National Natural Sciences Foundation Key Program (81630071).

\section{Footnote}

Reporting Checklist: The authors have completed the Narrative Review reporting checklist. Available at https:// dx.doi.org/10.21037/tlcr-21-572

Peer Review File: Available at https://dx.doi.org/10.21037/ tlcr-21-572
Conflicts of Interest: All authors have completed the ICMJE uniform disclosure form (available at https://dx.doi. org/10.21037/tlcr-21-572). The authors have no conflicts of interest to declare.

Ethical Statement: The authors are accountable for all aspects of the work in ensuring that questions related to the accuracy or integrity of any part of the work are appropriately investigated and resolved.

Open Access Statement: This is an Open Access article distributed in accordance with the Creative Commons Attribution-NonCommercial-NoDerivs 4.0 International License (CC BY-NC-ND 4.0), which permits the noncommercial replication and distribution of the article with the strict proviso that no changes or edits are made and the original work is properly cited (including links to both the formal publication through the relevant DOI and the license). See: https://creativecommons.org/licenses/by-nc-nd/4.0/.

\section{References}

1. Siegel RL, Miller KD, Fuchs HE, et al. Cancer Statistics, 2021. CA Cancer J Clin 2021;71:7-33.

2. Sung H, Ferlay J, Siegel RL, et al. Global Cancer Statistics 2020: GLOBOCAN Estimates of Incidence and Mortality Worldwide for 36 Cancers in 185 Countries. CA Cancer J Clin 2021;71:209-49.

3. Chen $\mathrm{W}$, Zheng R, Baade PD, et al. Cancer statistics in China, 2015. CA Cancer J Clin 2016;66:115-32.

4. Sharma SV, Bell DW, Settleman J, et al. Epidermal growth factor receptor mutations in lung cancer. Nat Rev Cancer 2007;7:169-81.

5. Kosaka T, Yatabe Y, Endoh H, et al. Mutations of the epidermal growth factor receptor gene in lung cancer: biological and clinical implications. Cancer Res 2004;64:8919-23.

6. Mendelsohn J, Baselga J. Status of epidermal growth factor receptor antagonists in the biology and treatment of cancer. J Clin Oncol 2003;21:2787-99.

7. Jänne PA, Engelman JA, Johnson BE. Epidermal growth factor receptor mutations in non-small-cell lung cancer: implications for treatment and tumor biology. J Clin Oncol 2005;23:3227-34.

8. Han SW, Kim TY, Hwang PG, et al. Predictive and prognostic impact of epidermal growth factor receptor mutation in non-small-cell lung cancer patients treated with gefitinib. J Clin Oncol 2005;23:2493-501. 
9. Shi Y, Au JS, Thongprasert S, et al. A prospective, molecular epidemiology study of EGFR mutations in Asian patients with advanced non-small-cell lung cancer of adenocarcinoma histology (PIONEER). J Thorac Oncol 2014;9:154-62.

10. Engelman JA, Jänne PA. Factors predicting response to EGFR tyrosine kinase inhibitors. Semin Respir Crit Care Med 2005;26:314-22.

11. Mok TS, Wu YL, Thongprasert S, et al. Gefitinib or carboplatin-paclitaxel in pulmonary adenocarcinoma. $\mathrm{N}$ Engl J Med 2009;361:947-57.

12. Maemondo M, Inoue A, Kobayashi K, et al. Gefitinib or chemotherapy for non-small-cell lung cancer with mutated EGFR. N Engl J Med 2010;362:2380-8.

13. Crinò L, Cappuzzo F, Zatloukal P, et al. Gefitinib versus vinorelbine in chemotherapy-naive elderly patients with advanced non-small-cell lung cancer (INVITE): a randomized, phase II study. J Clin Oncol 2008;26:4253-60.

14. Sun JM, Lee KH, Kim SW, et al. Gefitinib versus pemetrexed as second-line treatment in patients with nonsmall cell lung cancer previously treated with platinum-based chemotherapy (KCSG-LU08-01): an open-label, phase 3 trial. Cancer 2012;118:6234-42.

15. Mitsudomi T, Morita S, Yatabe Y, et al. Gefitinib versus cisplatin plus docetaxel in patients with non-small-cell lung cancer harbouring mutations of the epidermal growth factor receptor (WJTOG3405): an open label, randomised phase 3 trial. Lancet Oncol 2010;11:121-8.

16. Wu YL, Zhou C, Liam CK, et al. First-line erlotinib versus gemcitabine/cisplatin in patients with advanced EGFR mutation-positive non-small-cell lung cancer: analyses from the phase III, randomized, open-label, ENSURE study. Ann Oncol 2015;26:1883-9.

17. Zhou C, Wu YL, Chen G, et al. Final overall survival results from a randomised, phase III study of erlotinib versus chemotherapy as first-line treatment of EGFR mutation-positive advanced non-small-cell lung cancer (OPTIMAL, CTONG-0802). Ann Oncol 2015;26:1877-83.

18. Zhou C, Wu YL, Chen G, et al. Erlotinib versus chemotherapy as first-line treatment for patients with advanced EGFR mutation-positive non-small-cell lung cancer (OPTIMAL, CTONG-0802): a multicentre, open-label, randomised, phase 3 study. Lancet Oncol 2011;12:735-42.

19. Karampeazis A, Voutsina A, Souglakos J, et al. Pemetrexed versus erlotinib in pretreated patients with advanced nonsmall cell lung cancer: a Hellenic Oncology Research
Group (HORG) randomized phase 3 study. Cancer 2013;119:2754-64.

20. Wu YL, Zhou C, Cheng Y, et al. Erlotinib as second-line treatment in patients with advanced non-small-cell lung cancer and asymptomatic brain metastases: a phase II study (CTONG-0803). Ann Oncol 2013;24:993-9.

21. Rosell R, Carcereny E, Gervais R, et al. Erlotinib versus standard chemotherapy as first-line treatment for European patients with advanced EGFR mutation-positive non-small-cell lung cancer (EURTAC): a multicentre, open-label, randomised phase 3 trial. Lancet Oncol 2012;13:239-46.

22. Schuler M, Wu YL, Hirsh V, et al. First-Line Afatinib versus Chemotherapy in Patients with Non-Small Cell Lung Cancer and Common Epidermal Growth Factor Receptor Gene Mutations and Brain Metastases. J Thorac Oncol 2016;11:380-90.

23. Wu YL, Zhou C, Hu CP, et al. Afatinib versus cisplatin plus gemcitabine for first-line treatment of Asian patients with advanced non-small-cell lung cancer harbouring EGFR mutations (LUX-Lung 6): an open-label, randomised phase 3 trial. Lancet Oncol 2014;15:213-22.

24. Sequist LV, Yang JC, Yamamoto N, et al. Phase III study of afatinib or cisplatin plus pemetrexed in patients with metastatic lung adenocarcinoma with EGFR mutations. J Clin Oncol 2013;31:3327-34.

25. Kato T, Yoshioka H, Okamoto I, et al. Afatinib versus cisplatin plus pemetrexed in Japanese patients with advanced non-small cell lung cancer harboring activating EGFR mutations: Subgroup analysis of LUX-Lung 3. Cancer Sci 2015;106:1202-11.

26. Wu YL, Cheng Y, Zhou X, et al. Dacomitinib versus gefitinib as first-line treatment for patients with EGFRmutation-positive non-small-cell lung cancer (ARCHER 1050): a randomised, open-label, phase 3 trial. Lancet Oncol 2017;18:1454-66.

27. Mok TS, Cheng Y, Zhou X, et al. Improvement in Overall Survival in a Randomized Study That Compared Dacomitinib With Gefitinib in Patients With Advanced Non-Small-Cell Lung Cancer and EGFR-Activating Mutations. J Clin Oncol 2018;36:2244-50.

28. Soria JC, Ohe Y, Vansteenkiste J, et al. Osimertinib in Untreated EGFR-Mutated Advanced Non-Small-Cell Lung Cancer. N Engl J Med 2018;378:113-25.

29. Ramalingam SS, Vansteenkiste J, Planchard D, et al. Overall Survival with Osimertinib in Untreated, EGFR-Mutated Advanced NSCLC. N Engl J Med 2020;382:41-50. 
30. Mok TS, Wu Y-L, Ahn M-J, et al. Osimertinib or Platinum-Pemetrexed in EGFR T790M-Positive Lung Cancer. N Engl J Med 2017;376:629-40.

31. Akamatsu H, Katakami N, Okamoto I, et al. Osimertinib in Japanese patients with EGFR T790M mutation-positive advanced non-small-cell lung cancer: AURA3 trial. Cancer Sci 2018;109:1930-8.

32. Wu YL, Ahn MJ, Garassino MC, et al. CNS Efficacy of Osimertinib in Patients With T790M-Positive Advanced Non-Small-Cell Lung Cancer: Data From a Randomized Phase III Trial (AURA3). J Clin Oncol 2018;36:2702-9.

33. Nie K, Zhang Z, Zhang C, et al. Osimertinib compared docetaxel-bevacizumab as third-line treatment in EGFR T790M mutated non-small-cell lung cancer. Lung Cancer 2018;121:5-11.

34. Pao W, Miller VA, Politi KA, et al. Acquired resistance of lung adenocarcinomas to gefitinib or erlotinib is associated with a second mutation in the EGFR kinase domain. PLoS Med 2005;2:e73.

35. Sequist LV, Waltman BA, Dias-Santagata D, et al. Genotypic and histological evolution of lung cancers acquiring resistance to EGFR inhibitors. Sci Transl Med 2011;3:75ra26.

36. Yu HA, Arcila ME, Rekhtman N, et al. Analysis of tumor specimens at the time of acquired resistance to EGFR-TKI therapy in 155 patients with EGFR-mutant lung cancers. Clin Cancer Res 2013;19:2240-7.

37. Thress KS, Paweletz CP, Felip E, et al. Acquired EGFR C797S mutation mediates resistance to AZD9291 in nonsmall cell lung cancer harboring EGFR T790M. Nat Med 2015;21:560-2.

38. Jia Y, Yun CH, Park E, et al. Overcoming EGFR(T790M) and $\mathrm{EGFR}(\mathrm{C} 797 \mathrm{~S})$ resistance with mutant-selective allosteric inhibitors. Nature 2016;534:129-32.

39. Zhang Q, Zhang XC, Yang JJ, et al. EGFR L792H and G796R: Two Novel Mutations Mediating Resistance to the Third-Generation EGFR Tyrosine Kinase Inhibitor Osimertinib. J Thorac Oncol 2018;13:1415-21.

40. Hanahan D, Coussens LM. Accessories to the crime: functions of cells recruited to the tumor microenvironment. Cancer Cell 2012;21:309-22.

41. Quail DF, Joyce JA. Microenvironmental regulation of tumor progression and metastasis. Nat Med 2013;19:1423-37.

42. Mantovani A, Allavena P, Sica A, et al. Cancer-related inflammation. Nature 2008;454:436-44.

43. Shapouri-Moghaddam A, Mohammadian S, Vazini H, et al. Macrophage plasticity, polarization, and function in health and disease. J Cell Physiol 2018;233:6425-40.

44. Li Z, Maeda D, Yoshida M, et al. The intratumoral distribution influences the prognostic impact of CD68and CD204-positive macrophages in non-small cell lung cancer. Lung Cancer 2018;123:127-35.

45. Saruwatari K, Ikemura S, Sekihara K, et al. Aggressive tumor microenvironment of solid predominant lung adenocarcinoma subtype harboring with epidermal growth factor receptor mutations. Lung Cancer 2016;91:7-14.

46. Feng PH, Yu CT, Chen KY, et al. S100A9+ MDSC and TAM-mediated EGFR-TKI resistance in lung adenocarcinoma: the role of RELB. Oncotarget 2018;9:7631-43.

47. Qian BZ, Pollard JW. Macrophage diversity enhances tumor progression and metastasis. Cell 2010;141:39-51.

48. Zhang B, Zhang Y, Zhao J, et al. M2-polarized macrophages contribute to the decreased sensitivity of EGFR-TKIs treatment in patients with advanced lung adenocarcinoma. Med Oncol 2014;31:127.

49. Waisman A, Lukas D, Clausen BE, et al. Dendritic cells as gatekeepers of tolerance. Semin Immunopathol 2017;39:153-63.

50. Venugopalan A, Lee MJ, Niu G, et al. EGFR-targeted therapy results in dramatic early lung tumor regression accompanied by imaging response and immune infiltration in EGFR mutant transgenic mouse models. Oncotarget 2016;7:54137-56.

51. Yu S, Sha H, Qin X, et al. EGFR E746-A750 deletion in lung cancer represses antitumor immunity through the exosome-mediated inhibition of dendritic cells. Oncogene 2020;39:2643-57.

52. Nigro A, Ricciardi L, Salvato I, et al. Enhanced Expression of CD47 Is Associated With Off-Target Resistance to Tyrosine Kinase Inhibitor Gefitinib in NSCLC. Front Immunol 2020;10:3135.

53. Waldhauer I, Steinle A. NK cells and cancer immunosurveillance. Oncogene 2008;27:5932-43.

54. Tu C, Zhu Y, Jiang B, et al. Correlation between circulating tumor cells EGFR expression and T cell subsets in advanced non-small cell lung cancer patients after tyrosine kinase inhibitor treatment. Neoplasma 2017;64:619-25.

55. Park HR, Ahn YO, Kim TM, et al. NK92-CD16 cells are cytotoxic to non-small cell lung cancer cell lines that have acquired resistance to tyrosine kinase inhibitors. Cytotherapy 2019;21:603-11.

56. He S, Yin T, Li D, et al. Enhanced interaction between natural killer cells and lung cancer cells: involvement 
in gefitinib-mediated immunoregulation. J Transl Med 2013;11:186.

57. Kumar V, Patel S, Tcyganov E, et al. The Nature of Myeloid-Derived Suppressor Cells in the Tumor Microenvironment. Trends Immunol 2016;37:208-20.

58. Gabrilovich DI. Myeloid-Derived Suppressor Cells. Cancer Immunol Res 2017;5:3-8.

59. Feng PH, Chen KY, Huang YC, et al. Bevacizumab Reduces S100A9-Positive MDSCs Linked to Intracranial Control in Patients with EGFR-Mutant Lung Adenocarcinoma. J Thorac Oncol 2018;13:958-67.

60. Liew PX, Kubes P. The Neutrophil's Role During Health and Disease. Physiol Rev 2019;99:1223-48.

61. Zhang Y, Feng YC, Zhu HG, et al. The peripheral blood neutrophil-to-lymphocyte ratio is a prognostic predictor for survival of EGFR-mutant nonsmall cell lung cancer patients treated with EGFR-TKIs. Medicine (Baltimore) 2018;97:e11648.

62. Meriggi F, Codignola C, Beretta GD, et al. Significance of neutrophil-to-lymphocyte ratio in Western advanced EGFR-mutated non-small cell lung cancer receiving a targeted therapy. Tumori 2017;103:443-8.

63. Lin GN, Peng JW, Liu PP, et al. Elevated neutrophil-tolymphocyte ratio predicts poor outcome in patients with advanced non-small-cell lung cancer receiving first-line gefitinib or erlotinib treatment. Asia Pac J Clin Oncol 2017;13:e189-94.

64. Mansuet-Lupo A, Alifano M, Pécuchet N, et al. Intratumoral Immune Cell Densities Are Associated with Lung Adenocarcinoma Gene Alterations. Am J Respir Crit Care Med 2016;194:1403-12.

65. Franchina DG, Grusdat M, Brenner D. B-Cell Metabolic Remodeling and Cancer. Trends Cancer 2018;4:138-50.

66. Wang C, Yin R, Dai J, et al. Whole-genome sequencing reveals genomic signatures associated with the inflammatory microenvironments in Chinese NSCLC patients. Nat Commun 2018;9:2054.

67. Germain C, Gnjatic S, Tamzalit F, et al. Presence of B cells in tertiary lymphoid structures is associated with a protective immunity in patients with lung cancer. Am J Respir Crit Care Med 2014;189:832-44.

68. Lohr M, Edlund K, Botling J, et al. The prognostic relevance of tumour-infiltrating plasma cells and immunoglobulin kappa $\mathrm{C}$ indicates an important role of the humoral immune response in non-small cell lung cancer. Cancer Lett 2013;333:222-8.

69. Bruno TC, Ebner PJ, Moore BL, et al. Antigen-Presenting Intratumoral B Cells Affect CD4+ TIL Phenotypes in
Non-Small Cell Lung Cancer Patients. Cancer Immunol Res 2017;5:898-907.

70. Cai X, Zhang L, Wei W. Regulatory B cells in inflammatory diseases and tumor. Int Immunopharmacol 2019;67:281-6.

71. Zhang Y, Gallastegui N, Rosenblatt JD. Regulatory B cells in anti-tumor immunity. Int Immunol 2015;27:521-30.

72. Kumar BV, Connors TJ, Farber DL. Human T Cell Development, Localization, and Function throughout Life. Immunity 2018;48:202-13.

73. Borghaei H, Paz-Ares L, Horn L, et al. Nivolumab versus Docetaxel in Advanced Nonsquamous Non-Small-Cell Lung Cancer. N Engl J Med 2015;373:1627-39.

74. Rittmeyer A, Barlesi F, Waterkamp D, et al. Atezolizumab versus docetaxel in patients with previously treated non-small-cell lung cancer (OAK): a phase 3, openlabel, multicentre randomised controlled trial. Lancet 2017;389:255-65.

75. Lisberg A, Cummings A, Goldman JW, et al. A Phase II Study of Pembrolizumab in EGFR-Mutant, PD-L1+, Tyrosine Kinase Inhibitor Naïve Patients With Advanced NSCLC. J Thorac Oncol 2018;13:1138-45.

76. Zhang XC, Wang J, Shao GG, et al. Comprehensive genomic and immunological characterization of Chinese non-small cell lung cancer patients. Nat Commun 2019;10:1772.

77. Simoni Y, Becht E, Fehlings M, et al. Bystander CD8+ T cells are abundant and phenotypically distinct in human tumour infiltrates. Nature 2018;557:575-9.

78. Biton J, Mansuet-Lupo A, Pécuchet N, et al. TP53, STK11, and EGFR Mutations Predict Tumor Immune Profile and the Response to Anti-PD-1 in Lung Adenocarcinoma. Clin Cancer Res 2018;24:5710-23.

79. Dong ZY, Zhang JT, Liu SY, et al. EGFR mutation correlates with uninflamed phenotype and weak immunogenicity, causing impaired response to PD-1 blockade in non-small cell lung cancer. Oncoimmunology 2017;6:e1356145.

80. Mazzaschi G, Madeddu D, Falco A, et al. Low PD-1 Expression in Cytotoxic CD8+ Tumor-Infiltrating Lymphocytes Confers an Immune-Privileged Tissue Microenvironment in NSCLC with a Prognostic and Predictive Value. Clin Cancer Res 2018;24:407-19.

81. Busch SE, Hanke ML, Kargl J, et al. Lung Cancer Subtypes Generate Unique Immune Responses. J Immunol 2016;197:4493-503.

82. Datar I, Sanmamed MF, Wang J, et al. Expression Analysis and Significance of PD-1, LAG-3, and TIM-3 in Human 
Non-Small Cell Lung Cancer Using Spatially Resolved and Multiparametric Single-Cell Analysis. Clin Cancer Res 2019;25:4663-73.

83. Chen N, Fang W, Zhan J, et al. Upregulation of PDL1 by EGFR Activation Mediates the Immune Escape in EGFR-Driven NSCLC: Implication for Optional Immune Targeted Therapy for NSCLC Patients with EGFR Mutation. J Thorac Oncol 2015;10:910-23.

84. Sugiyama E, Togashi Y, Takeuchi Y, et al. Blockade of EGFR improves responsiveness to PD-1 blockade in EGFR-mutated non-small cell lung cancer. Sci Immunol 2020;5:eaav3937.

85. Watanabe S, Hayashi H, Haratani K, et al. Mutational activation of the epidermal growth factor receptor down-regulates major histocompatibility complex class I expression via the extracellular signal-regulated kinase in non-small cell lung cancer. Cancer Sci 2019;110:52-60.

86. Shimizu K, Okita R, Saisho $\mathrm{S}$, et al. Prognostic value of Cox-2 and PD-L1 expression and its relationship with tumor-infiltrating lymphocytes in resected lung adenocarcinoma. Cancer Manag Res 2017;9:741-50.

87. Liu SY, Dong ZY, Wu SP, et al. Clinical relevance of PD$\mathrm{L} 1$ expression and CD8+ T cells infiltration in patients with EGFR-mutated and ALK-rearranged lung cancer. Lung Cancer 2018;125:86-92.

88. Haratani K, Hayashi H, Tanaka T, et al. Tumor immune microenvironment and nivolumab efficacy in EGFR mutation-positive non-small-cell lung cancer based on T790M status after disease progression during EGFRTKI treatment. Ann Oncol 2017;28:1532-9.

89. Meniawy TM, Lake RA, McDonnell AM, et al. PD-L1 on peripheral blood $\mathrm{T}$ lymphocytes is prognostic in patients with non-small cell lung cancer (NSCLC) treated with EGFR inhibitors. Lung Cancer 2016;93:9-16.

90. Chen K, Cheng G, Zhang F, et al. PD-L1 expression and $T$ cells infiltration in patients with uncommon EGFRmutant non-small cell lung cancer and the response to immunotherapy. Lung Cancer 2020;142:98-105.

91. Waldmann TA. Cytokines in Cancer Immunotherapy. Cold Spring Harb Perspect Biol 2018;10:a028472.

92. Wang DH, Lee HS, Yoon D, et al. Progression of EGFRMutant Lung Adenocarcinoma is Driven By Alveolar Macrophages. Clin Cancer Res 2017;23:778-88.

93. Jiang XM, Xu YL, Huang MY, et al. Osimertinib (AZD9291) decreases programmed death ligand-1 in EGFR-mutated non-small cell lung cancer cells. Acta Pharmacol Sin 2017;38:1512-20.

94. Wang S, Zhang Y, Wang Y, et al. Amphiregulin Confers
Regulatory T Cell Suppressive Function and Tumor Invasion via the EGFR/GSK-3ß/Foxp3 Axis. J Biol Chem 2016;291:21085-95.

95. Tsukita Y, Fujino N, Miyauchi E, et al. Axl kinase drives immune checkpoint and chemokine signalling pathways in lung adenocarcinomas. Mol Cancer 2019;18:24.

96. Joseph NA, Chiou SH, Lung Z, et al. The role of HGFMET pathway and CCDC66 cirRNA expression in EGFR resistance and epithelial-to-mesenchymal transition of lung adenocarcinoma cells. J Hematol Oncol 2018;11:74.

97. Yano S, Yamada T, Takeuchi S, et al. Hepatocyte growth factor expression in EGFR mutant lung cancer with intrinsic and acquired resistance to tyrosine kinase inhibitors in a Japanese cohort. J Thorac Oncol 2011;6:2011-7.

98. Yamada T, Takeuchi S, Kita K, et al. Hepatocyte growth factor induces resistance to anti-epidermal growth factor receptor antibody in lung cancer. J Thorac Oncol 2012;7:272-80.

99. Yamada T, Matsumoto K, Wang W, et al. Hepatocyte growth factor reduces susceptibility to an irreversible epidermal growth factor receptor inhibitor in EGFRT790M mutant lung cancer. Clin Cancer Res 2010;16:174-83.

100.Han JY, Kim JY, Lee SH, et al. Association between plasma hepatocyte growth factor and gefitinib resistance in patients with advanced non-small cell lung cancer. Lung Cancer 2011;74:293-9.

101. Yano S, Wang W, Li Q, et al. Hepatocyte growth factor induces gefitinib resistance of lung adenocarcinoma with epidermal growth factor receptor-activating mutations. Cancer Res 2008;68:9479-87.

102. Gusenbauer S, Vlaicu P, Ullrich A. HGF induces novel EGFR functions involved in resistance formation to tyrosine kinase inhibitors. Oncogene 2013;32:3846-56.

103. Tanaka H, Kimura T, Kudoh S, et al. Reaction of plasma hepatocyte growth factor levels in non-small cell lung cancer patients treated with EGFR-TKIs. Int J Cancer 2011;129:1410-6.

104. Kasahara K, Arao T, Sakai K, et al. Impact of serum hepatocyte growth factor on treatment response to epidermal growth factor receptor tyrosine kinase inhibitors in patients with non-small cell lung adenocarcinoma. Clin Cancer Res 2010;16:4616-24.

105.Jiao D, Chen J, Li Y, et al. miR-1-3p and miR-206 sensitizes HGF-induced gefitinib-resistant human lung cancer cells through inhibition of c-Met signalling and EMT. J Cell Mol Med 2018;22:3526-36. 
106.Zhang Y, Zeng Y, Liu T, et al. The canonical TGF- $\beta /$ Smad signalling pathway is involved in PD-L1-induced primary resistance to EGFR-TKIs in EGFR-mutant non-smallcell lung cancer. Respir Res 2019;20:164.

107.Zhang L, Li QX, Wu HL, et al. SNPs in the transforming growth factor- $\beta$ pathway as predictors of outcome in advanced lung adenocarcinoma with EGFR mutations treated with gefitinib. Ann Oncol 2014;25:1584-90.

108. Soucheray M, Capelletti M, Pulido I, et al. Intratumoral Heterogeneity in EGFR-Mutant NSCLC Results in Divergent Resistance Mechanisms in Response to EGFR Tyrosine Kinase Inhibition. Cancer Res 2015;75:4372-83.

109.Zhu Q, Zhang Z, Lu C, et al. Gefitinib promotes CXCR4dependent epithelial to mesenchymal transition via TGF- $\beta 1$ signaling pathway in lung cancer cells harboring EGFR mutation. Clin Transl Oncol 2020;22:1355-63.

110.Abera MB, Kazanietz MG. Protein kinase C $\alpha$ mediates erlotinib resistance in lung cancer cells. Mol Pharmacol 2015;87:832-41.

111. Shen H, Guan D, Shen J, et al. TGF- $\beta 1$ induces erlotinib resistance in non-small cell lung cancer by downregulating PTEN. Biomed Pharmacother 2016;77:1-6.

112.Izumchenko E, Chang X, Michailidi C, et al. The TGF $\beta$ miR200-MIG6 pathway orchestrates the EMT-associated kinase switch that induces resistance to EGFR inhibitors. Cancer Res 2014;74:3995-4005.

113.Tamura T, Kato Y, Ohashi K, et al. Potential influence of interleukin-6 on the therapeutic effect of gefitinib in patients with advanced non-small cell lung cancer harbouring EGFR mutations. Biochem Biophys Res Commun 2018;495:360-7.

114. Nilsson MB, Sun H, Diao L, et al. Stress hormones promote EGFR inhibitor resistance in NSCLC: Implications for combinations with $\beta$-blockers. Sci Transl Med 2017;9:eaao4307.

115.Jia Y, Li X, Zhao C, et al. Impact of serum vascular endothelial growth factor and interleukin-6 on treatment response to epidermal growth factor receptor tyrosine kinase inhibitors in patients with non-small-cell lung cancer. Lung Cancer 2018;125:22-8.

116. Umeguchi H, Sueoka-Aragane N, Kobayashi N, et al. Usefulness of plasma HGF level for monitoring acquired resistance to EGFR tyrosine kinase inhibitors in non-small cell lung cancer. Oncol Rep 2015;33:391-6.

117. Cho JH, You YM, Yeom YI, et al. RNF25 promotes gefitinib resistance in EGFR-mutant NSCLC cells by inducing NF- $\kappa \mathrm{B}$-mediated ERK reactivation. Cell Death Dis 2018;9:587.
118. Ge P, Cao L, Chen X, et al. miR-762 activation confers acquired resistance to gefitinib in non-small cell lung cancer. BMC Cancer 2019;19:1203.

119. Fernando RI, Hamilton DH, Dominguez C, et al. IL-8 signaling is involved in resistance of lung carcinoma cells to erlotinib. Oncotarget 2016;7:42031-44.

120. Karachaliou N, Cardona AF, Bracht JWP, et al. Integrinlinked kinase (ILK) and src homology 2 domaincontaining phosphatase 2 (SHP2): Novel targets in EGFRmutation positive non-small cell lung cancer (NSCLC). EBioMedicine 2019;39:207-14.

121. Wang X, Zhang F, Yang X, et al. Secreted Phosphoprotein 1 (SPP1) Contributes to Second-Generation EGFR Tyrosine Kinase Inhibitor Resistance in Non-Small Cell Lung Cancer. Oncol Res 2019;27:871-7.

122.Zhou J, Wang J, Zeng Y, et al. Implication of epithelialmesenchymal transition in IGF1R-induced resistance to EGFR-TKIs in advanced non-small cell lung cancer. Oncotarget 2015;6:44332-45.

123. Becker JH, Gao Y, Soucheray M, et al. CXCR7 Reactivates ERK Signaling to Promote Resistance to EGFR Kinase Inhibitors in NSCLC. Cancer Res 2019;79:4439-52.

124. Frantz C, Stewart KM, Weaver VM. The extracellular matrix at a glance. J Cell Sci 2010;123:4195-200.

125. Lo HW, Hsu SC, Xia W, et al. Epidermal growth factor receptor cooperates with signal transducer and activator of transcription 3 to induce epithelial-mesenchymal transition in cancer cells via up-regulation of TWIST gene expression. Cancer Res 2007;67:9066-76.

126.Hugo HJ, Wafai R, Blick T, et al. Staurosporine augments EGF-mediated EMT in PMC42-LA cells through actin depolymerisation, focal contact size reduction and Snail1 induction - a model for cross-modulation. BMC Cancer 2009;9:235.

127.Zuo JH, Zhu W, Li MY, et al. Activation of EGFR promotes squamous carcinoma SCC10A cell migration and invasion via inducing EMT-like phenotype change and MMP-9-mediated degradation of E-cadherin. J Cell Biochem 2011;112:2508-17.

128.Zuo J, Wen M, Li S, et al. Overexpression of CXCR4 promotes invasion and migration of non-small cell lung cancer via EGFR and MMP-9. Oncol Lett 2017;14:7513-21.

129. Wang Y, Zhang T, Guo L, et al. Stromal extracellular matrix is a microenvironmental cue promoting resistance to EGFR tyrosine kinase inhibitors in lung cancer cells. Int J Biochem Cell Biol 2019;106:96-106.

130. Kalluri R, Zeisberg M. Fibroblasts in cancer. Nat Rev 
Cancer 2006;6:392-401.

131.Yi Y, Zeng S, Wang Z, et al. Cancer-associated fibroblasts promote epithelial-mesenchymal transition and EGFRTKI resistance of non-small cell lung cancers via HGF/ IGF-1/ANXA2 signaling. Biochim Biophys Acta Mol Basis Dis 2018;1864:793-803.

132. Ishibashi M, Neri S, Hashimoto H, et al. CD200-positive cancer associated fibroblasts augment the sensitivity of Epidermal Growth Factor Receptor mutation-positive lung adenocarcinomas to EGFR Tyrosine kinase inhibitors. Sci Rep 2017;7:46662.

133. Yoshida T, Ishii G, Goto K, et al. Podoplaninpositive cancer-associated fibroblasts in the tumor microenvironment induce primary resistance to EGFRTKIs in lung adenocarcinoma with EGFR mutation. Clin Cancer Res 2015;21:642-51.

134.Arena S, Salati M, Sorgentoni G, et al. Characterization of tumor-derived mesenchymal stem cells potentially differentiating into cancer-associated fibroblasts in lung cancer. Clin Transl Oncol 2018;20:1582-91.

135. Carmeliet P. Angiogenesis in health and disease. Nat Med 2003;9:653-60.

136.Pugh CW, Ratcliffe PJ. Regulation of angiogenesis by hypoxia: role of the HIF system. Nat Med 2003;9:677-84.

137. Ferrara N, Gerber HP, LeCouter J. The biology of VEGF and its receptors. Nat Med 2003;9:669-76.

Cite this article as: Liu L, Wang C, Li S, Bai H, Wang J. Tumor immune microenvironment in epidermal growth factor receptor-mutated non-small cell lung cancer before and after epidermal growth factor receptor tyrosine kinase inhibitor treatment: a narrative review. Transl Lung Cancer Res 2021;10(9):3823-3839. doi: 10.21037/tlcr-21-572
138. Togashi Y, Masago K, Kubo T, et al. Association between vascular-poor area of primary tumors and epidermal growth factor receptor gene status in advanced lung adenocarcinoma. Med Oncol 2012;29:3169-75.

139. Yuan XH, Yang J, Wang XY, et al. Association between EGFR/KRAS mutation and expression of VEGFA, VEGFR and VEGFR2 in lung adenocarcinoma. Oncol Lett 2018;16:2105-12.

140.Koizumi H, Yamada T, Takeuchi S, et al. Hsp90 inhibition overcomes HGF-triggering resistance to EGFR-TKIs in EGFR-mutant lung cancer by decreasing client protein expression and angiogenesis. J Thorac Oncol 2012;7:1078-85.

141.Nakade J, Takeuchi S, Nakagawa T, et al. Triple inhibition of EGFR, Met, and VEGF suppresses regrowth of HGFtriggered, erlotinib-resistant lung cancer harboring an EGFR mutation. J Thorac Oncol 2014;9:775-83.

142.Lee JG, Wu R. Erlotinib-cisplatin combination inhibits growth and angiogenesis through c-MYC and HIF-1 $\alpha$ in EGFR-mutated lung cancer in vitro and in vivo. Neoplasia 2015;17:190-200.

143. Nakagawa K, Garon EB, Seto T, et al. Ramucirumab plus erlotinib in patients with untreated, EGFRmutated, advanced non-small-cell lung cancer (RELAY): a randomised, double-blind, placebo-controlled, phase 3 trial. Lancet Oncol 2019;20:1655-69. 